\title{
African students from refugee backgrounds in Australian TAFE institutions: a case for transformative learning goals and processes
}

\author{
Gerald Onsando \\ Refugee Health Research Centre, La Trobe University \\ Stephen Billett \\ Griffith Institute for Educational Research, Griffith University
}

\begin{abstract}
Australian Technical and Further Education (TAFE) institutions are perhaps the most heterogeneous of the nation's educational sectors. However, TAFE institutions' capacity to provide inclusive education is constrained by their curriculum focus and pedagogical practices and culturally premised assumptions that may inhibit learning for students from diverse cultural backgrounds and life experiences. This paper reports a study that investigated the experiences of learning for African students from refugee backgrounds in TAFE institutions. Adopting phenomenological methodology, the study illuminates ways in which the students' earlier and current experiences shape their learning at TAFE institutions. The findings indicate that, while greatly appreciating being in a safe environment, African students from refugee backgrounds nevertheless experience racial discrimination and social exclusion as they resettle in Australia. Also, the pedagogical practices at TAFE institutions do not always recognise or accommodate the students' socio-cultural backgrounds and refugee life experiences. In all, the 'experienced curriculum' created unhelpful dissonances for these students. Consequently, the paper argues that in order to benefit more fully from their educational experiences in TAFE and more effectively engage in Australian society, including employment, African students from refugee backgrounds require particular interventions from these institutions and those who teach in them. It is proposed that a transformative learning approach is required for these students in TAFE institutions.
\end{abstract}

\section{Readiness to learn and needs for social inclusion}

I left my home country Sudan, fleeing from war ... Under care of my parents at the age of 8 ; I never expected to be separated from my parents, as war broke out unexpectedly. My dad was among the victims. At that time of brutal civil war in Sudan, we fled to Ethiopia with my mother, siblings other relatives, where we were accommodated by the UNHCR [United Nations High Commissioner for Refugees] in the Ethiopian camp for 4 years. ... war broke out again in Ethiopia ... As a result; my mother, brother and I trekked over 120 kilometres on foot to Kenya border without food or water. On our arrival at the Kenyan border in early 1992 the UNHCR received us. With refugee numbers increasing, UNHCR protection office at the Kenya-border decided to take us to Kakuma Camp [Turkana district, Kenya]. This is where I had stayed for 13 years before I came to Australia. (Participant/Sudan) 
This paper focuses on the experiences of learning for African students from refugee backgrounds whilst participating in Australian Technical and Further Education (TAFE) institutes. These institutes are a key component of the Australian vocational education and training (VET) system, which is the most heterogeneous of the nation's educational sectors, in terms of student backgrounds, age, range of qualifications and kinds of courses undertaken (e.g., Queensland Government 2008). As part of its charter, there is an expectation that the VET system will have a broadly inclusive education provision. Yet, the capacity to provide inclusive education is constrained by the system's educational purposes and prescribed curriculum, which almost exclusively focuses on securing industry-derived national competencies (Billett 2004; Chappell 2004; Junor 2005). Moreover, the pedagogical practices at TAFE institutions may not always promote optimal learning for students from diverse cultural backgrounds and life experiences (Ben-Moshe, Bertone, \& Grossman 2008). Certainly, students who have lived a number of years in refugee camps are likely to have significant challenges when engaging with the Australian TAFE learning curricula and therefore require particular interventions to assist with their engagement and outcomes. Earlier cultural and life experiences, described as pre-mediate (Valsiner 2000), serve to shape how individuals make sense of what they experience, that is, how they construe and construct what they subsequently experience. This process of experiencing includes individuals' sense of self or subjectivity, arising through participation in activities and interactions that shape how the individuals interpret and engage with what they subsequently encounter (Billett 2009). This then is a key premise of how, for example, African students from refugee backgrounds engage in and learn from what they encounter in educational institutions. For these students, education needs to be transforming, as they seek to learn, live and work in their newly and quite distinct adopted country. Yet, the provision of a transformative education requires a clear understanding of how both the students' socio-cultural heritage and refugee life experiences may affect their learning activities, and how learning experiences can productively assist these students to reach particular learning goals.

This paper argues that, for these students in particular, the learning experiences in TAFE institutions have to acknowledge the cultural heritages, norms and practices that these students associate with; acknowledge and respond to their often disrupted educational backgrounds; yet offer a provision that enables them to move progressively towards more productive lives in Australia. This paper presents, as a way of proceeding, a brief overview of what African socio-cultural backgrounds and refugee life experiences may entail. The method, 
approach and the key findings from the study are then presented, and are followed by a discussion of how TAFE institutions can utilise the transformative learning approach to provide meaningful support to the African students from refugee backgrounds. In conclusion, it is proposed that the Australian VET system should create a learning environment that fosters transformative learning for African students from refugee backgrounds in TAFE institutions.

\section{African socio-cultural backgrounds}

The socially derived cultural heritage of many African people comprises subcultures that cannot easily be described or interpreted under a single definition. However, a common identifier amongst many African socio-cultural values and practices is the emphasis and promotion of community, rather than individual lifestyles (Nsubuga-Kyobe 2007). These socio-cultural practices can lead to particular ways of knowing and engaging with others. For example, where transfer of knowledge is concerned, as in the teaching-learning nexus, the socio-cultural practices are likely to extend to one's epistemological beliefs (Hofer 2006). These beliefs arise through individuals' life histories: They are learnt (Billett 2009). In Australia, learning is mainly guided by a curriculum that fosters individualism, whereas African socio-cultural practices encourage group-generated ways of knowledge acquisition and problem solving (Trevino \& Davids 2001). The African socio-cultural derived ways of communicating and transferring knowledge are also quite distinct from the predominantly visual-verbal culture common in Australia (New South Wales Government 2006). This difference implies that learning activities focussing on individual effort and reward may be in conflict with the epistemological beliefs of students with African traditional, social and cultural heritage. Indeed, for many students, their migration to Australia likely represents a fundamental change of environments, traditions, cultures, and pedagogical practices, of which the practices of educational institutions are just one part. Therefore, exposure in educational settings to experiences to which the students are unaccustomed may serve to exacerbate an attachment to familiar practices, rather than assist the students to develop perspectives about and competence in the kinds of cultural practices they will require to live productive lives in Australia.

Further, as discussed in the next section, some students from refugee backgrounds, as a result of their past refugee life experiences, are likely to display psychological stress symptoms (Coventry et al. 2002; Multicultural Affairs Queensland (MAQ) 2008). These 
kinds of pre-mediate experiences may intensify the impact of discomforting and noninvitational experiences they encounter in TAFE institutions.

\section{Refugee life experiences}

A starting point for the consideration of the earlier experiences of students from refugee backgrounds and the likely consequences for their learning through TAFE institutions is provided by the UNHRC. That Convention defines a refugee as a person, who "owing to a well-founded fear of being persecuted for reasons of race, religion, nationality, membership of a particular social group, or political opinion" (UNHCR 2007, p. 16) has fled from their country of origin. Coventry et al. (2002 pp. 14-15) further characterised refugee life experiences as having the following typical series of events:

exposure to political, religious or intercultural violence, persecution or oppression, armed conflict or civil discord which incorporates the following basic elements: a state of fearfulness for self and family members; leaving the country of origin at short notice; inability to return to the country of origin; and uncertainty about the possibility of maintaining links with family and home. (Coventry, Guerra, Mackenzie, and Pinkney, 2002, pp. 14-15)

The physical and mental health burden resulting from such refugee life experiences is likely to affect individuals' education and training activities (Cassity \& Gow 2005). During resettlement, such refugee life experiences may lead to individuals displaying post traumatic stress disorder (PTSD) symptoms (MAQ 2001; Silove et al. 2007). Therefore, students from refugee backgrounds attending TAFE institutions courses are likely to be affected by the mental health related burdens resulting from their refugee life experiences, in addition to the consequences of disrupted educational histories.

Consequently, in contrast to many adult learning and development theories that advocate for the utilization of past experiences (Andersen, Boud \& Cohen 2000; Brookfield 1986; Knowles 1990; Merriam, Caffarella \& Baumgartner 2007), the pre-mediate experiences of students from refugee backgrounds may actively work against the process of participating in learning at TAFE institutions. However, such education experiences can serve as a basis from which individuals may transform their lives (Mezirow 1990; Taylor 1998) through securing new learning and capacities to engage more productively in social and economic life. Therefore, the issue of readiness to learn for students from refugee backgrounds is not just one of possessing the capacities to participate in the experiences, as in the Piagetian account (Billett 2006), but goes further to include both physical and psychological dissonance that the students might encounter during learning at TAFE 
institutions. It was these kinds of issues that motivated this research study, the approach and methodology of which is described and discussed next.

\section{Methodology}

Given the need to understand the experience of learning at TAFE institutions from the perspectives of students whose diverse cultural backgrounds and life experiences are different from those of students who typically participate in Australian vocational education, the study adapted the qualitative phenomenological methodology. This methodology seeks to describe individuals' experience of certain phenomena (van Manen 1990). This inquiry was aimed at understanding the kinds of experiences African students from refugee backgrounds faced. The study participants described their African heritage and previous refugee lifestyles, their migration to Australia, and their subsequent experiences of learning at TAFE institutions. In order to clarify the participants" experiences of "what it means to be" (van Manen 1990, p. 183) an African student from a refugee background engaged in learning at TAFE institutions, the ontological philosophical assumption was adopted. This means that the participants' descriptions of experiences and perceptions were provided through the use of statements with direct quotes and themes (Creswell 1998). This procedure was aimed at securing fidelity in response to the data collected and the data presented.

The participants in this study were all African students from refugee backgrounds participating in studies at a TAFE institution in a metropolitan Australian city. The participants selected were from the African countries of Sudan, Liberia, Ethiopia and Burundi because these countries represented many of the recent Australian offshore refugee visa grants (Refugee Council of Australia (RCOA) 2006). They were 5 males and 5 females, aged between 23 and 53 years old. This selection was made in order to obtain responses from both genders and to obtain views of students who have spent different periods of times in their studies at TAFE. Data collection was enacted through in-depth face-to-face interviews. All interviews were conducted primarily in English, although where appropriate some participants preferred to use the Swahili language which is also spoken by the researcher who conducted the interviews. All interviews were audio-recorded for transcription purposes, and field notes were also made from observations during the interview. The thematic data analysis adapted procedures outlined by Moustakas (1994) and involved listing out the significant statements from the participants, describing their experiences, and, thereafter, identifying the emerging themes from the descriptions of experiences. The participants' 
names and other identifiers have been altered such that the study conforms to the privacy and confidentiality requirements of ethical conduct ofinquiry.

\section{Key challenges facing African students from refugee backgrounds}

The findings of the study clearly indicate that African students from refugee backgrounds face a number of social exclusion practices at TAFE institutions. Two key themes emerged from the thematic analysis. The themes are (i) racial discrimination and socio-cultural exclusion, and (ii) pedagogical practices and personal histories. Overall, these findings suggest that the students' learning challenges in unfamiliar socio-cultural environments have been exacerbated by their refugee life experiences. The study also revealed that the curriculum enacted in the TAFE institutions was not particularly invitational for these students and that some teachers lacked an appreciation of the students' socio-cultural and refugee life backgrounds. The participants also reported that although Australia was a relatively safe environment, they often confronted racial discrimination acts against them. Their descriptions of experiences formed the basis of the study findings which are now discussed, in turn.

\section{Racial discrimination and socio-cultural exclusion}

A key concern expressed by the participants was the perceived incidents of racial discrimination they encountered. One participant from Sudan held that racial discrimination was an issue of concern that made him feel isolated and uneasy. He stated that "I usually feel isolated. If you are given team work ... they run away from you." This participant further explained that this isolation made him unmotivated to attend lessons. A number of other participants shared this view. They claimed that eradicating racial discrimination acts against them would go a long way in solving many of the challenges they faced when engaged in learning at TAFE institutions. For example, this participant stated:

Absolutely I do [think there is racial discrimination] and this gives me much stress by not concentrating very well sometimes! Yeah, it has been happening, it has been happening. Especially, when doing group work activities, they keep you out; they assume their ideas are more appropriate than yours. We students from the non-English speaking background, we have been pushed aside, by teachers, through our assignments, through our ideas ... by tutors, and other students. Yeah, that's right. (Participant/Sudan)

The effects of racial discrimination extended to the participants' feelings of being isolated and stereotyped as inferior beings. For many, such social injustices and prejudices were an unwelcome source of distress and discomfort additional to their existing learning challenges. 
These experiences were likely to discourage many of the participants from achieving their educational and vocational goals at TAFE institutions. Other than racial discrimination, participants also expressed how they experienced learning challenges in unfamiliar sociocultural environments in Australia. The participants gave an overview of how, for example, family gender roles, and traditional, cultural and social practices in their countries of origin differed from what they experience here in Australia:

In Burundi, generally the man controls everything - he is the head of the house. Here it seems everybody over 18 can do what they want - it seems so different. In our culture we learn to respect our parents - for example, you cannot marry without permission of the elders or the community. ... One of the good cultures - they teach people [in Australia is] to be responsible persons - that is very good. (Participant/Burundi)

There are all sorts of African traditional and cultural practices ranging from foodstuff, poems, storytelling to dances. We the Dinka are river-lake Nilotes and are cattle keepers. We make a lot of initiation marks on our foreheads and are strongly guided by our parents. ... [Life in Australia is] totally different, very, very different ... everything absolutely different. ... It would be good if teachers could understand students' life and not just giving or teaching and go away. (Participant/Sudan)

I used to tell my teacher "we have some other things we need to give to you - you need to consider our background, our culture - it may help you know how to handle different persons." (Participant /Burundi)

These illustrative quotes indicate how the participants felt excluded by being in unfamiliar socio-cultural environments. For many of the students, these differences created a barrier against their interaction and engagement with teachers and other students at TAFE institutions who did not share their socio-cultural backgrounds. The participants also confirmed that, although overwhelmed by unfamiliar ways of living in Australia, they nevertheless were impressed by a number of social practices here. For these students, being in Australia placed them in unfamiliar socio-cultural environments which confronted them with expectations and practices that were quite alien, hence the lack of capacity they needed to reconcile these differences unaided. These circumstances are exemplified in the struggles many of them reported with the pedagogic practices in TAFE institutions.

\section{Pedagogical practices and personal histories}

A number of participants indicated that their backgrounds were often ignored by some pedagogical practices applied by teachers. For example, participants felt that teachers, while planning for lessons, should acknowledge the refugees' life backgrounds and also consider their often limited competence in using computers. Indeed, some participants attributed their 
lack of progress in TAFE institutions to the teachers' lack of understanding their personal histories and enactment of inappropriate pedagogical practices. According to a participant, this situation is especially dire to some of the elderly students:

Oh dear ... I think they [teachers] need to know somehow where the refugees come from ... the way they teach those old people now, they will never, never learn English, never, never! Most people will complete the mandatory 510 hours for learning English, but they don't improve, then they go back to Centrelink for more hours. (Participant/Sudan)

Here [in Australia], because of the [computer technology] facilities, teachers are not giving much information. One teacher was saying, "we have everything [about spelling] in our computers - we will do it [spell checks] in our computer'. (Participant /Liberia)

These descriptions indicate that there was a general concern among participants that some teachers were unable to understand and acknowledge their backgrounds, and that some teachers made excessive use of unfamiliar terms about computer technology during learning. This problem was further exacerbated the fact that many participants lacked adequate English language communication skills as a result of having previously communicated in languages other than English. Hence, the students struggle to comprehend at the rate that their teachers might expect of them. The participants' personal histories characterised by refugee life experiences also emerged as an issue. It became evident that after participants fled from war, persecution, and other related atrocities in their home countries, their life at the refugee camps was also punctuated by regular cases of extreme violence and acute shortage of food. Four of the participants summarised these experiences with the following statements:

[During the initial flight] It took us one month to reach Ethiopia - and we walked day and night. Many people died everyday at that time because of diseases like ... diarrhoea, because there was no toilets. [At the refugee camps] it was very horrible, so depressing and frustrating. The only positive experience I had is ... this suffering and this poverty ... has shown me not be selfish in my life. [In Australia] it is a big jump, big change. But it is safer to be here - now it at least helps us to be ourselves, rely on ourselves. (Participant/Sudan)

I cannot forget, even now, what happened to me. It was very bad - I found myself in Australia without knowing where the rest of my family was. Life in the refugee camp was the worst one ... I find that Australia is a peaceful country. Here we get enough food - that is a very good thing. (Participant/Ethiopia)

They [memories of traumatic experiences] are not frequent, but sometimes [I have] some nightmares about the camp. These issues cannot just disappear; it takes quite a long time. Even sometimes if I get a call from the refugees that 'we are suffering, now we are in trouble', even if I go to school, I will still have to mind that a lot of my colleagues are not in a good condition. I may pretend that I am in class, but I am not doing anything - my mind is thinking about this problem - this affects a lot. (Participant/Burundi)

Because of the [community] activities I was involved in; of course I had so many enemies. Perpetrators didn't like what I was doing to protect the vulnerable people ... So some of them 
were very cross to me and some threatened my family till I had to leave. So the UNHCR found a way to bring me out - am very happy that the Australian government responded positively in one month after they heard about my story. (Participant /Burundi)

Many participants reported similar cases of experiencing violence and death in their home countries and the trauma of the violence then spreading to the refugee camps to which they had fled for safety and shelter. They all shared the feeling of being safe in Australia. Yet, due to such high prevalence of insecurity and violence in the refugee camps, many participants expressed concern about the safety of their family members who remained there. This feeling of apprehension about the safety of their family members was a source of psychological distress. The participants reported that those who teach them in TAFE institutions needed to be more aware of and sensitive to their often difficult personal histories, and how this left them to be personally fragile and sensitive to threats to their well-being.

This issue is taken up in the following section, which draws on the interview data in discussing how the Australian VET system can enact in TAFE institutions transformative learning environments that recognise and appreciate the pre-mediate experiences of African students from refugee backgrounds. This paper argues that the social disadvantages occasioned by the students' earlier or pre-mediate experiences can be redressed in part through the creation of transformative learning environments that afford the students more invitational experiences at TAFE institutions.

\section{Transformative learning at TAFE institutions}

The transformative learning theories mainly emerged from the works of Freire (1995), Habermas (1971) and Mezirow (1981), all of whom advocated for meaningful social change through education. Freire (1995) used the concept of 'conscientisation' to enlighten learners about the dynamics of the society in which they live, with a purpose of changing their limiting and taken-for-granted social roles. Habermas (1971) advanced 'emancipatory learning' as a learning domain which involved the learner's self-understanding within the context of their historical background, current standing, and future expectations. Mezirow (1981) argued for learners' empowerment through change from long-held constraining beliefs. Transformative learning theories are aimed at emancipating learners from their disadvantaged situations by making meaningful and empowering life changes in them (Inglis 1997; Cranton 1994). O'Sullivan, Morrell and O'Connor (2002, p. xvii; p. 11) described what transformative learning entails: 
Transformative learning involves experiencing a deep, structural shift in the basic premises of thought, feelings, and actions. It is a shift of consciousness that dramatically and permanently alters our way of being in the world. Such a shift involves our understanding of ourselves and our self-locations; our relationships with other humans and with the natural world; our understanding of relations of power in interlocking structures of class, race, and gender; our body-awareness, our visions of alternative approaches to living; and our sense of possibilities for social justice and peace and personal joy.

For learners to experience these transformative changes of perspective, they need to be ready to learn (Cohen \& Piper 2000), while educators need to establish meaningful and authentic relationships with them (Cranton 2006). Educators can foster such authentic relationships by motivating their learners to overcome learning barriers as a result of their disadvantaged past experiences. Transformative learning therefore may offer unique life changing opportunities to students who typically have been disadvantaged by living a significant amount of their lives in refugee camps with little or no formal schooling. Moreover, transformative learning practices offer the prospect for meaningful life changes to learners irrespective of their levels of formal education (Wright, Cranton \& Quigley 2007). For example, the Catalyst-Clemente programme, which is based on transformative learning principles, has successfully been used to empower socially disadvantaged populations in Australia (Howard et al. 2008).

For many African students from refugee backgrounds, being in TAFE institutions placed them in distinctly unfamiliar socio-cultural environments that confronted them with expectations and practices that were quite alien. Therefore, to advance social inclusion and transformative practices for these students, some bridging is required between their existing ways of knowing and capacities, and what is required of them to participate more productively in learning. Importantly, from a curriculum and pedagogical perspective, the students' experiencing of transformative learning at TAFE institutions is salient. The curriculum is seen as having three key manifestations: (i) the intended curriculum - what is intended to be taught and learnt; (ii) the enacted curriculum - what is enacted by teachers and others, and the circumstances of its enactment; and (iii) the experienced curriculum - what students experience and, therefore, learn from their engagement with what is enacted. For many, the experienced curriculum is the most important as it ultimately determines what is learnt. The same applies to pedagogy. Students from refugee backgrounds who may be facing socio-cultural and possible psychological distress issues require the experience of transformative learning curriculum that will enable them to have a "greater sense of purpose and meaning" (Tolliver \& Tisdell 2006, p. 37). 
It is acknowledged that TAFE institutions provide support in many ways to these students. However, this support can be much more meaningful, socially inclusive and life transforming. Australian TAFE institutions can potentially provide a curriculum and an environment where such transformative learning experiences can be practiced (Hodge 2008). It is therefore incumbent for TAFE institutions and teachers to respectively formulate and enact a transformative curriculum in order for the African students from refugee backgrounds to experience new ways of living through learning. These goals can be attained through: (a) TAFE institutions' provision of a conducive and a social inclusive learning environment where racial discrimination is not tolerated; (b) students enhancing their readiness to learn by committing to new ways of living; (c) teachers recognition of the students' refugee life premediate experiences; and (d) TAFE institutions' accommodation of the students' sociocultural pre-mediate experiences. These processes are now discussed in turn.

\section{Social inclusive learning environments}

Racial discrimination is a form of social exclusion (Saloojee 2003) and racial prejudices targeted at students from refugee backgrounds are likely to adversely affect their settlement and educational outcomes in Australia (Matthews 2008; Olliff 2004; O’Sullivan \& Olliff 2006). Such racial subordination will likely "offend, insult, humiliate or intimidate" (Healey 2003, p. 4) individuals or communities making them feel isolated. Indeed, African students from refugee backgrounds who faced racial discrimination found it harder to co-exist socially with the mainstream population because of the feeling of being excluded from the society (Allender 1998; Taylor 2004). Concerns about how racism and racial discrimination might affect students from refugee backgrounds at TAFE institutions extend to the very reasons that anti-racial discrimination legislation has been introduced in Australia. In granting resettlement opportunities on humanitarian grounds to refugees, the Australian government has identified and recognised that these individuals have previously suffered grievously. Therefore, that recognition needs to extend to ensuring that further disadvantage and negative experiences that can result from social exclusion and racial discrimination be eliminated from the experiences of these students whilst in Australia.

TAFE institutes' authorities can, therefore, offer support to African refugee students by regularly hosting educational programs in conjunction with the government, legal experts, the African communities, and other relevant bodies who can come together to diagnose, offer remedies, and assist in implementing solutions to the problem. Such forums and programs then can serve to educate the general public about the circumstances which refugees have 
undergone prior to their arrival in Australia. These forums and programs could be organised to target staff and students, and, therefore, might conveniently be hosted and conducted by the TAFE institutes themselves. The outcomes of the forums and programs are expected to foster social inclusive learning environments at TAFE institutions. It is appreciated that education authorities, in many other ways, have acknowledged the importance of cultural and racial harmony within their institutions. However, it is also worth noting that there was a time when these issues would have been addressed by the TAFE curriculum through life skills and general education provisions. But these areas of the curriculum have often been eliminated or de-emphasised as the focus on industry related content has become the central concern (Billett 2004). Consequently, some of these provisions might be returned to both assist with more general education outcomes and through the use of these to assist the students adapt to different processes of learning in Australian educational institutions.

\section{Students' readiness to learn}

Students' transformative learning needs can be addressed through a consideration of their readiness to participate in learning at TAFE institutions. This consideration can focus on the extent to which the learners understand how their socio-cultural backgrounds and refugee life experiences have come to constrain their wellbeing in Australia. For this to happen, the students will be expected, at times, to adapt to changes that will often be in conflict with their personal and communal ways of living. Taylor (1994) termed this adaptation to new cultures as "intercultural competency" (p. 155), while Mezirow (1981) referred to it as "perspective transformation" which he described as:

the emancipatory process of becoming critically aware of how and why the structure of psycho-cultural assumptions has come to constrain the way we see ourselves and our relationships, reconstituting this structures to permit a more inclusive and discriminating integration of experience and acting upon these new understandings. (Mezirow, 1981, p. 6)

The learners' critical awareness of new ways of social engagement (Cohen \& Piper 2000) and adapting those engagements through transformative learning can be supported by the Australian VET system. For example, to ease the students' process of adapting to new forms of social engagement, the transformative learning environments at TAFE institutions are expected to offer a curriculum that recognises their diverse cultural backgrounds and past refugee life experiences. This will lay a solid foundation of learning and living in new environments for students. Another possible way that a transformative learning curriculum can be experienced by students from refugee backgrounds is through the use of their refugee 
life experiences as the basis of effecting change. Students' past traumatic experiences may serve as "disorienting dilemma" (Mezirow 1981, p. 7), which can be the premise for their engaging in transformative learning. Indeed, according to Pierce (as cited by Taylor 1998), past disturbing experiences can be a motivation for the learners to transform how they perceive the world:

The disturbing events in the participant's lives, therefore, create a fertile ground for perspective transformation. Ready to question the very assumptions upon which their lives are based, these participants found themselves involved in an educational experience which encourages a search for meaning, an exploration of oneself and fulfilment of Human purpose. (as cited by Taylor 1998, p. 16)

These disorienting dilemmas can be followed at TAFE institutions by students' learning and reintegration of new experiences which reinforce a more positive living. The commitment to new ways of living as a result of past disturbing events in students' lives is expected to enhance their readiness to engage in learning. In fact, according to Snyder (2008), an authentic transformative learning curriculum should focus more on how emotions from such disturbing events can be transformed into positive learning experiences, as opposed to purely focusing on the learners' cognitive experiences and needs.

\section{Refugee life pre-mediate experiences}

Given their difficult experiences it is easy to admire the students from refugee backgrounds for their resilience and resolve to engage in learning at TAFE institutions. This resolve should not be overlooked considering how the students' past experiences have come to shape their current status, and capacities to participate effectively in educational provisions. Instead, consideration of the students' past experiences should guide how the teachers at TAFE institutions can engage with these students, and the consequences of the learning outcomes they attain from TAFE institutions. On the account of that some of the students may still suffer from psychological distress resulting from their refugee life experiences, Feinstein et al. (2006) argued that engaging them with appropriate pedagogical practices may have a positive effect upon their mental and physical health. Indeed, Hammond (2004) reported that meaningful education engagement led to better physical health and general "recovery from mental difficulties" (p. 553). For many students from refugee backgrounds, perhaps for the first time in their lives, they have real opportunities to choose and embark on life pathways that empower them through education. Therefore, for these students engaging in learning activities also doubles as a way of transforming themselves from parts of their past with 
which they wish to disassociate, into new productive ways of living. It is because of this life transformation, through learning, that teachers at TAFE institutions are encouraged to use transformative learning theory (Cranton 2002; Lacefield 1999) to alter the students' disadvantaged positions.

Teachers should be more aware of their students' refugee life pre-mediate experiences. Increased awareness might assist teachers to use appropriate pedagogical practices when facilitating these students' learning (Cranton 2006). The Australian VET system can encourage and support professional development that educates TAFE teachers about refugee life experiences and the resulting mental health issues. This education will ensure that teachers are sensitive to their students' past experiences, and will therefore assist them to put appropriate pedagogical practices in place. These professional development activities can be conducted through partnership with community such organisations as the Forum of Australian Services for Survivors of Torture and Trauma (FASSTT), whose agencies are located in each state and territory of Australia. These agencies provide various rehabilitation and counselling services to communities mainly from refugee backgrounds who have suffered trauma prior to migrating to Australia. These kinds of sessions should be directed towards maximising the known benefits of meaningful education upon the learners' physical and mental health (Feinstein et al. 2006). Another way of reinforcing the psychological support at TAFE institutions would be the adaptation of Allender's (1998) proposal, which recommended that all educators involved with students from refugee backgrounds should be specially trauma-therapy-trained, such that they can provide appropriate and immediate assistance when required. Of particular relevance here in bridging students' personal refugee life experiences with their new life in Australia is the enactment of a pedagogy that initially reflects and is sensitive to what they have previously experienced as refugees. Such an approach should be intended not to accommodate their preferences per se, but to find safe and conducive means that engage them as learners and introduce them into a more self-directed approach to the type of learning that is common in Australian educational institutions. That is, a pedagogy that is sensitive to refugee students' backgrounds ought to aim to provide a bridge to living and working in a country whose cultural milleau is quite different from what the students have previously experienced.

\section{Socio-cultural pre-mediate experiences}

The resettlement of African students from refugee backgrounds in Australia likely represents a fundamental change of environments, traditions, and cultures to them. Indeed, many of the 
students may transfer particular kinds of concepts from their cultural heritage into the learning environment in Australia. These indigenous African socio-cultural pre-mediate concepts are likely to be different from the ways of learning in Australia. This difference may result in the students experiencing difficulties in learning and communication, and hence prohibit effective learning outcomes at TAFE institutions. Moreover, according to the New South Wales Government (2006) report, the African refugee students' learning outcomes in Australia are likely to be adversely affected by their socio-cultural backgrounds because:

Both learning and communication in Australia involve the mastery of complex written and technological skills. Learning in Africa may have been markedly different for many of the entrants. Communication techniques in a predominantly oral-aural culture (in Africa) are very different from those required in a visual-verbal culture (in Australia). (New South Wales Government 2006, p. 89)

The differences in modes of communication can result in the risk of dissonance between the social environment and pedagogical practices in Australian TAFE institutions. This dissonance may also lead to significant social and communication barriers in the students' educational progression, and thereby adversely affect their readiness to engage in the kinds of learning being provided by TAFE institutions. It is therefore quite likely that African students' socio-cultural backgrounds may hinder their effective engagement in the intended learning activities in TAFE institutions. The process of knowledge construction and learning is likely to be highly influenced by the learners' socio-cultural practices (Billett 1998). Therefore, for African students' from refugee backgrounds, the approaches to teaching and learning at TAFE institutions may be quite different from what they may have experienced before; the approaches represent distinct methods by which to experience the curriculum, and they make the engagement in learning a formidable task

Catering for socio-culturally oriented learning challenges requires many students to access supportive learning environments that reinforce their socio-cultural practices. For example, in collaboration with local community associations (like the Queensland African Communities Council (QACC)), there might be some consideration of how African traditional and cultural activities can be part of the pedagogic practices. Another way of cushioning the detrimental effects of socio-cultural differences faced by African students from a refugee background would be the assigning of suitable African peer mentors who would assist the students through the initial stages of settlement and learning in Australia. The peer mentors could play a role in working with the teachers to develop their capacities, sympathies and empathies. Yet, it is clearly understood that these measures should not be 
enacted at the expense of the students' interaction with other members of the wider Australian community.

In all, it is important that education and training authorities encourage teachers to be more aware of and sensitive to African traditions and cultural practices. This increased awareness may assist them, as educators, to understand their learners' backgrounds and provide more authentic learning experiences for their students. For instance, to assist an enhanced understanding of these cultures, educational institutions could organise orientation programs where learners and educators freely exchange their basic cultural practices and experiences. It is appreciated that because most of teachers do not possess the African sociocultural backgrounds this may be a difficult, although necessary, task for them. Importantly, these activities may well assist in achieving the kinds of resettlement goals that governments have set for African students from refugee backgrounds, while on the other hand assist in the development of the kinds of knowledge, attitudes and skills required for their full socioeconomic participation in Australia.

\section{Social implications}

Clearly, the presence of African students from refugee backgrounds in Australian postsecondary classrooms presents issues and perhaps problems for teachers and administrators. In particular, these students have particular backgrounds, goals, and personal motivations for participating in learning which are probably not entirely understood by teachers and the VET system. Certainly, the extent to which the students' goals and motivations are achieved through engagement in learning may be determined by the extent to which education authorities understand and acknowledge their situation. It is, therefore, desirable and necessary for teachers and administrators to understand and be sensitive to the scope and kinds of experiences that the students from refugee backgrounds have previously encountered. It is also incumbent on the Australian VET system to formulate a curriculum that will assist the students from refugee backgrounds to transform into more meaningful lives in their new country. If the students are not appropriately and adequately supported by education authorities, there is real concern that they may be excluded and marginalised by Australian society and, hence, potentially pose a threat to the country's social fabric and never have the opportunity to realise their potential and contribution to the country. Importantly, the evidence suggests that these students want to be socially included in the Australian society, and to contribute to and be active citizens of their new home country. 
So, there are important social imperatives that go beyond arguments regarding the provision of support and equity, but which are associated with maintaining a society that is inclusive of the reasonable aspirations and needs of its members. The kinds of dislocation and frustrations resulting from long term perception of social exclusion may be comparable to the recent race-related riots in France and Australia (Maynard 2006). In many ways, what the Australian government has done in providing African refugees with sanctuary and a new life is humane and commendable. But for these individuals, being granted access and initial support to realise fulfilling lives - the very objective of Australia's Humanitarian Program may not be realised unless educational institutions and those who work in them are provided with the resources to secure this goal. Resettlement issues, including education and training, facing refugee entrants from African countries are problems which the Australian government and the education and training system should give due attention. Humanitarian arrivals may find that adjust socially and culturally to the Australian society is easier if they receive recognition and support from the general population. This is a valid case for the Australian federal and state governments, in conjunction with education and training authorities, to develop public education programs that will help the Australian population understand people from refugee backgrounds as social beings with specific needs that arise from their past disadvantaged status.

\section{A transformative curriculum within TAFE}

This paper has addressed the readiness to learn and need for social inclusion of African students from refugee backgrounds attending TAFE institutions in Australia. An educational provision that focuses on transformative experiences is proposed to be best placed to secure the engagement of these students and facilitate the changes that are required for them to live and work productively in Australia. This case has been advanced through a consideration of the students' socio-cultural backgrounds, their past refugee life experiences and the possibility of 'empowering' them through transformative learning. It has clearly emerged that the students face a number of challenges, ranging from experiencing racial discrimination and social exclusion, to teachers at TAFE institutions enacting pedagogical practices that do not always recognise the students' socio-cultural backgrounds and refugee life experiences. In all, it is proposed that the better way to offer meaningful support to these students is by the Australian VET system, through TAFE institutions, providing a transformative learning environment that fosters socially inclusive learning environments and consideration of the students' refugee life and socio-cultural pre-mediate experiences. In order to experience 
transformative learning, the students are also expected to commit to readiness to learn. The social implications and the dangers of not adequately addressing these students' learning needs have also been discussed.

\section{References}

Allender, S C insert month written in full here 1998, Australia's immigrants and refugees: opening the door to lifelong learning. How Adults Learn, paper presented at the Adult Multicultural Education Services Australia.

Andersen, L, Boud, D \& Cohen, R 1998, Experience-based learning. In Understanding adult education and training, $2^{\text {nd }}$ edn, ed. G Foley, Allen \& Unwin, St Leonards, NSW,.

Ben-Moshe, D, Bertone, S \& Grossman, M, 2008, Refugee access and participation in tertiary education and training, Institute for Community, Ethnicity and Policy Alternatives (ICEPA), Melbourne.

Billett, S 1998, 'Ontogeny and participation in communities of practice: a socio-cognitive view of adult development', Studies in the Education of Adults, vol. 30, no. 1, pp. 2134.

Billett, S 2004, 'From your business to our business: industry and vocational education in Australia', Oxford Review of Education, vol. 30, no. 1, p. 12-33.

Billett, S 2006, 'Relational interdependence between social and individual agency in work and working life', Mind, Culture, and Activity, vol. 13, no.1, pp. 53-69.

Billett, S 2009, 'Conceptualizing learning experiences: contributions and mediations of the social, personal, and brute', Mind, Culture, and Activity, vol. 16, no. 1, pp. 32-47.

Brookfield, S D 1986, Understanding and facilitating adult learning: a comprehensive analysis of principles and effective practices. Open University Press, Milton Keynes.

Cassity, E \& Gow, G 2005, 'Making up for lost time: the experiences of Southern Sudanese young refugees in high schools', Youth Studies Australia, vol. 24, no. 3, pp. 51-55.

Chappell, C 2004, 'Contemporary vocational learning - changing pedagogy', Proceedings of the 7th Australian Vocational Education and Training Research Association (AVETRA) Conference, viewed 24 June 2008, http://www.avetra.org.au/Conference_Archives/2004/documents/PA013Chappell.pdf

Cohen, J B \& Piper, D 2000, 'Transformation in a residential adult learning community', In Learning as transformation: critical perspectives on a theory in progress, ed $\mathrm{J}$. Mezirow, Jossey-Bass, San Francisco.

Coventry, L, Guerra, C. MacKenzie, D \& Pinkney, S 2002, Wealth of all nations: identification of strategies to assist refugee young people in transition to independence, National Youth Affairs Research Scheme, Hobart, TAS. 
Cranton, P 1994, Understanding and promoting transformative learning: a guide for educators and adults. Jossey-Bass, San Francisco.

Cranton, P 2002, 'Teaching for transformation', New Directions for Adult and Continuing Education, vol. 93, pp. 63-71.

Cranton, P 2006, 'Fostering authentic relationships in the transformative classroom', New Directions for Adult and Continuing Education, vol. 109, pp. 5-13.

Creswell, J W 1998, Qualitative inquiry and research design: choosing among five traditions, Sage Publications Inc, Thousand Oaks, CA.

Feinstein, L, Sabates, R, Anderson, T M, Sorhaindo, A \& Hammond, C 2006, 'What are the effects of education on health?' In Measuring the effects of education on health and civic engagement: proceedings of the Copenhagen Symposium, ed. R Desjardins \& $\mathrm{T}$ Schuller, Organisation for Economic Co-operation and Development (OECD), Copenhagen.

Freire, P 1995, Pedagogy of the oppressed (M. B. Ramos, Trans.), The Continuum Publishing Company, New York.

Hammond, C 2004, 'Impacts of lifelong learning upon emotional resilience, psychological and mental health: fieldwork evidence', Oxford Review of Education, vol. 30, no. 4, pp. 551-568.

Habermas, J 1971, Knowledge and human interests. Bacon Press, Boston.

Healey, J (Ed.) 2003, Racism in Australia (Vol. 180). The Spinney Press, Rozelle, NSW.

Hodge, S Month 2008, Disorienting VET: enhancing VET practice through transformative learning theory, Paper presented at the $11^{\text {th }}$ annual conference of the Australian Vocational Education and Training Research Association (AVETRA).

Hofer, B K 2006, 'Beliefs about knowledge and knowing: integrating domain specificity and domain generality: a response to Muis, Bendixen, and Haerle', Educational Psychology Review, vol. 18, no. 1, pp. 67-76.

Howard, P, Marchant, T, Hampshire, A, Butcher, J, Egan, L, \& Bredhauer, K 2008, 'Promoting social inclusion: emerging evidence from the Catalyst-Clemente program', Australian Journal of Adult Learning, vol. 48, no. 3, pp. 479-501.

Inglis, T 1997, 'Empowerment and emancipation', Adult Education Quarterly, vol. 48, no. 1, pp. 3-17.

Junor, A 2005, 'Professionals, practitioners, peripheral product delivers: contested definitions of contingent TAFE teaching', Proceedings of the $19^{\text {th }}$ conference of the Association of Industrial Relations Academics of Australia and New Zealand (AIRAANZ), viewed $24 \quad$ June 2008, http://www.mngt.waikato.ac.nz/airaanz/proceedings/Sydney2005/Refereedpapers/Jun or.pdf 
Knowles, M S 1990, The adult learner: a neglected species, Gulf Publishing Company, Houston, TX.

Lacefield, R 1999, Adult education in practice: on being a transformative educator, viewed 15 July, 2006, http://members.tripod.com/ roberta/transform.htm

MAQ (Multicultural Affairs Queensland) 2001, Employment issues facing people of nonEnglish speaking background, Queensland Government, Brisbane.

MAQ (Multicultural Affairs Queensland) 2008, New Futures: the Queensland Government's engagement with African refugees. Queensland Government, Brisbane.

Matthews, J 2008, 'Schooling and settlement: refugee education in Australia', International Studies in Sociology of Educational Psychology Review, vol.18, no. 1, pp. 31-45.

Maynard, R 2006, Sydney beach riots 'fuelled by racial prejudice', The Guardian (October 20, 2006 ed.), Guardian News and Media Limited, Manchester.

Merriam, S B, Caffarella, R S \& Baumgartner, L M 2007, Learning in adulthood: a comprehensive guide, John Wiley \& Sons Inc, San Francisco, CA.

Mezirow, J 1981, 'A critical theory of adult learning and education', Adult Education, vol. 32, no. 1, pp. 3-24.

Mezirow, J 1990, 'Towards transformative learning and emancipatory education'. In Fostering critical reflection in adulthood: a guide to transformative and emancipatory learning, ed J Mezirow, Jossey-Bass, San Francisco.

Moustakas, C E 1994, Phenomenological research methods, Sage Publications, Thousand Oaks, CA.

New South Wales Government 2006, The report of the NSW Community Relations Commission investigation into African humanitarian settlement in NSW, viewed 15 May, 2006 http://www.crc.nsw.gov.au/publications/african/index.htm

Nsubuga-Kyobe, A 2007, 'A note on tensions in African-Australian families and the Australian Family Court', The Australasian Review of African Studies, vol. XXVIII, pp. 97-110.

Olliff, L 2004, Pathways and pitfalls: the journey of refugee young people in and around the education system in Greater Dandenong, Victoria. Centre for Multicultural Youth Issues (CMYI), Melbourne, VIC.

O'Sullivan, E, Morrell, A \& O'Connor, M A (Eds.) 2002, Expanding the boundaries of transformative learning: essays on theory and praxis. Palgrave, New York, N.Y.

O'Sullivan, K, \& Olliff, L 2006, Settling in: exploring good settlement for refugee young people in Australia. Centre for Multicultural Youth Issues (CMYI), Melbourne, VIC. 
Queensland Government 2008, Overview of TAFE Queensland, viewed 10 December, 2008, http://www.tafe.qld.gov.au/about_us/overview/index.html.

RCOA (Refugee Council of Australia) 2006, Australia's refugee and special humanitarian program: current issues and future directions. Views from the community sector, viewed 20 April 2006, http://www.refugeecouncil.org.au/arp/overview.html

Saloojee, A 2003, Social inclusion, anti-racism and democratic citizenship. The Laidlaw Foundation, Ontario, Canada.

Silove, D, Steel, Z, Bauman, A, Chey, T \& McFarlane, A 2007, 'Trauma, PTSD and the longer-term mental health burden amongst Vietnamese refugees: a comparison with the Australian-born population', Social Psychiatry and Psychiatric Epidemiology, vol. 42, no. 6, pp. 467-476.

Snyder, C 2008, 'Grabbing hold of a moving target: identifying and measuring the transformative learning process', Journal of Transformative Education, vol. 6, no. 3, pp. 159-181.

Taylor, E W 1994, 'Intercultural competency: a transformative learning process', Adult Education Quarterly, vol. 44, no. 3, pp. 154-174.

Taylor, E W 1998, The theory and practice of transformative learning: a critical review (No. RR93002001). ERIC Clearinghouse on Adult, Career, and Vocational Education, Columbus, Ohio.

Taylor, J 2004, 'Refugees and social exclusion: what the literature says', Migration Action, vol. XXVI, no. 2, pp. 16-31.

Tolliver, D E \& Tisdell, E J 2006, 'Engaging spirituality in the transformative higher education classroom', New Directions for Adult and Continuing Education, vol. 109, pp. 37-47.

Trevino, J, \& Davids, J 2001, 'Small action research project on ESL literacy and prelinguistic African women refugees' In Seeding literacy: adult educators research their practice, ed. J Davis \& J Searle, Language Australia Ltd, Melbourne VIC.

UNHCR (United Nations High Commission for Refugees) 2007, Convention and protocol relating to the status of refugees. $\mathrm{UNHCR}$, Geneva.

Valsiner, J 2000, Culture and human development. Sage Publications, London.

van Manen, M 1990, Researching lived experience: human science for an action sensitive pedagogy. State University of New York Press, London.

Wright, B, Cranton, P \& Quigley, B A June 2007, Literacy educators' perspectives on transformation and authenticity, paper presented at the 48th National Adult Education Research Conference (AERC) and the $26^{\text {th }}$ National Canadian Association for the Study of Adult Education (CASAE), Mount Saint Vincent University, Halifax, Nova Scotia. 